\title{
Host-guest interactions in nor-seco-cucurbit[10]uril: novel guest-dependent molecular recognition and stereoisomerism
}

\author{
Xiaodong Zhang, Wei Wu, Zhu Tao and Xin-Long Ni ${ }^{*}$
}

\author{
Full Research Paper \\ Address: \\ Key Laboratory of Macrocyclic and Supramolecular Chemistry of \\ Guizhou Province, Guizhou University, Guiyang 550025, China \\ Email: \\ Xin-Long Ni - longni333@163.com \\ ${ }^{*}$ Corresponding author \\ Keywords: \\ fluorescent; host-guest interaction; macrocycles; molecular \\ recognition; nor-seco-cucurbit[10]uril; pyrene
} \begin{abstract}
doi:10.3762/bjoc. 15.166
Received: 07 May 2019

Accepted: 09 July 2019

Published: 19 July 2019
\end{abstract}

Beilstein J. Org. Chem. 2019, 15, 1705-1711.

This article is part of the thematic issue "Novel macrocycles - and old ones doing new tricks".

Guest Editor: W. Jiang

(C) 2019 Zhang et al.; licensee Beilstein-Institut.

License and terms: see end of document.

\begin{abstract}
The unique monomer and excimer fluorescence emissions of pyrene were first exploited as distinctly photophysical signals to identify the possible diastereomers of guests within nor-seco-cucurbit[10]uril (NS-CB[10]) cavities. Further experiments revealed that balancing the hydrophilic and hydrophobic effects of the guest in aqueous solution can improve the molecular recognition and binding ability of NS-CB[10].
\end{abstract}

\section{Introduction}

Host-guest interactions that trigger molecular recognition are a current topic of interest. For example, understanding the protein-ligand molecular recognition is of paramount importance in the study of enzymatic catalysis and allosteric regulation of cell signaling, as well as in the design of efficient drugs that utilize host-guest interactions [1]. Cucurbit $[n]$ urils ( $\mathrm{Q}[n] \mathrm{s}$ or $\mathrm{CB}[n] \mathrm{s})[2,3]$ having been viewed to have high potential use in host-guest chemistry in aqueous solution because of their varying cavity rigidity and larger portal sizes as compared with those of other macrocyclic hosts [4-13]. For example, cucurbit[8]uril (Q[8] or CB[8]), a large homologue of the Q[n] family, is unique because of its ability to bind two hetero- and homo-aromatic guests in its cavity through host-stabilized charge-transfer or $\pi-\pi$ interactions $[14,15]$. This novel property of Q[8] has been utilized as molecular container for biological substrates [16,17], as well as in the construction of various supramolecular assemblies with specific structures and properties [18-22]. However, forming ternary complexes with Q[8] is challenging because the number of aromatic-derived watersoluble recognition motifs remains limited.

In 2006, Isaacs and co-workers reported the synthesis and isolation of nor-seco-cucurbit[10]uril (NS-CB[10], host-1, Scheme 1) [23], a new member of the extended $\mathrm{Q}[n]$ family that 
contains two identical cavities. Different from the Q[8] host, NS-CB[10] can not only accommodate two aromatic guest molecules such as 4,4-bipyridinium (viologen), but also has the ability to accommodate two other guest molecules such as adamantaneammonium (ADA) or alkylammonium ions into the cavity, forming a ternary complex. The novel binding capacity of NS-CB[10] has been utilized to form supramolecular polymers [24-26] and polymer nanoparticles [27]. More importantly, Isaacs et al. discovered that when the unsymmetrical guest ADA molecules are bound within NS-CB[10], three diastereomers such as top-top, center-center, and top-center can be observed. These diastereomers display homotropic allostery based on a guest-size-induced preorganization mechanism [23]. However, the same ADA guest was not incorporated into the cavity after NS-CB[10] was functionalized with imidazolidone (host2, Scheme 1) [28].

Herein, we report the supramolecular host-guest interactions of the two cavities of NS-CB[10]-based host-1 and host-2 with two unsymmetrical ADA-based derivatives (G1 and G2, Scheme 1). As expected, hosts-1 and - $\mathbf{2}$ are capable of simultaneously binding guest G1, thus forming 1:2 ternary complexes by including different groups of $\mathbf{G 1}$ into the cavity. For example, host-1 can accommodate the ADA moiety into the cavity, whereas host-2 tends to include the benzyl group into the cavity. This behavior may be attributed to the bridging imidazolidone units of host-2 that rigidify its structure and make it selective toward smaller guests. However, we found that the ADA group can be accommodated into the cavity of host-2 when a larger hydrophobic unit such as pyrene instead of a benzyl group was appended to the ADA scaffold (G2). Interestingly, the top-center isomer of G2 within both host-1 and host2 could be characterized because of the novel monomer and excimer photophysical property of pyrene as fluorophore. As a result, we demonstrated here a novel guest-controlled molecular recognition and stereoisomerism for the first time.

\section{Results and Discussion}

We took advantage of the two novel identical cavities and the simple formation of ternary diastereomer complexes with NS-CB[10]-based host-1 and host-2. The size of each cavity of host-1 is similar in size to Q[7], and the cavity size of host-2 is close to that of Q[6]. We first designed and prepared the ADA-benzyl-based ammonium guest molecules G1. We synthesized this compound because ADA can form a highly stable complex with Q[7] (the highest reported $K$ value for the ADA.Q[7] complex is $10^{12} \mathrm{M}^{-1}$ ) [29]; while benzylammonium ions can be included in both cavities of Q[7] and Q[6]. Figure 1
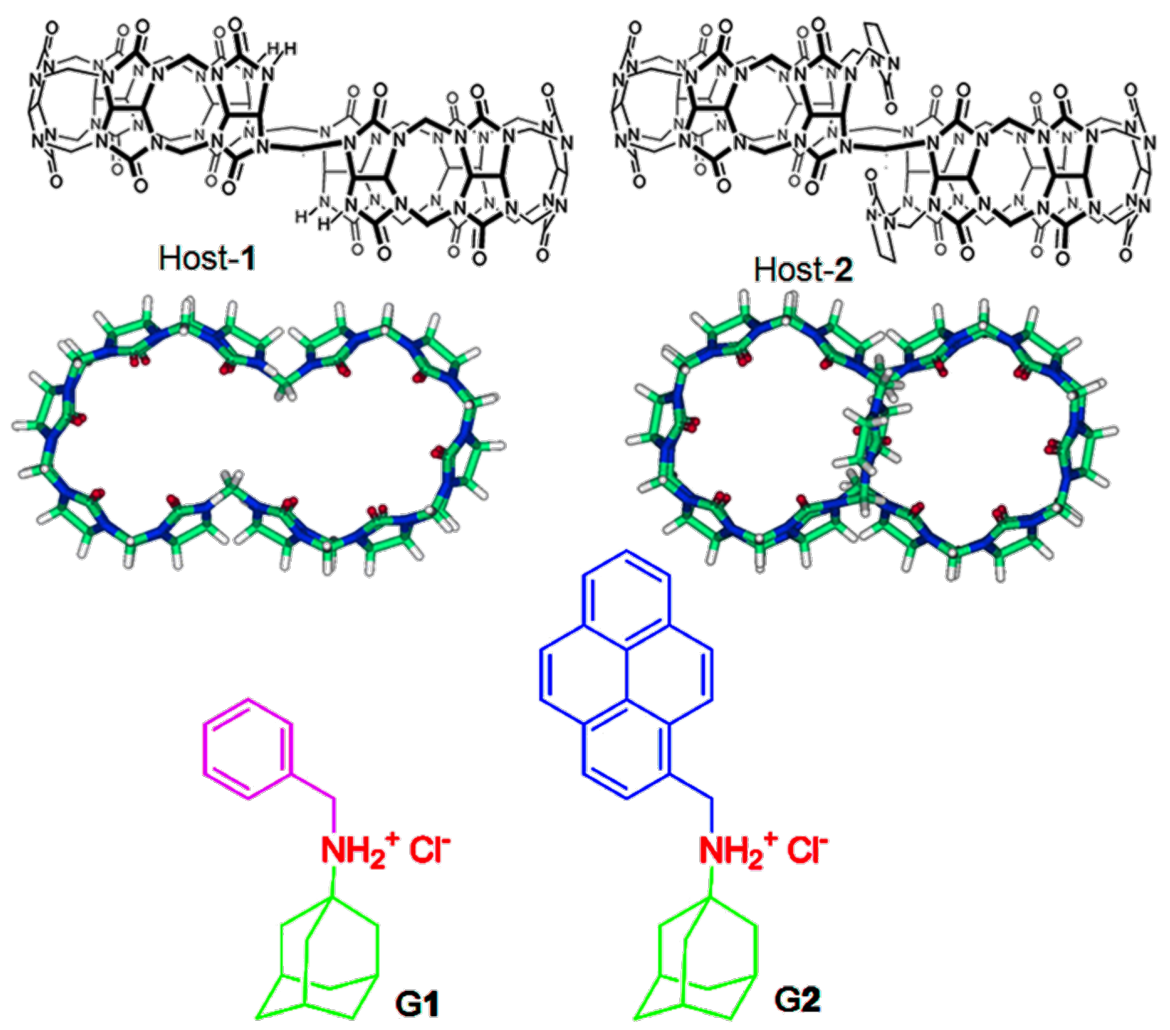

Scheme 1: Chemical structures of host-1, host-2, G1, and G2. 


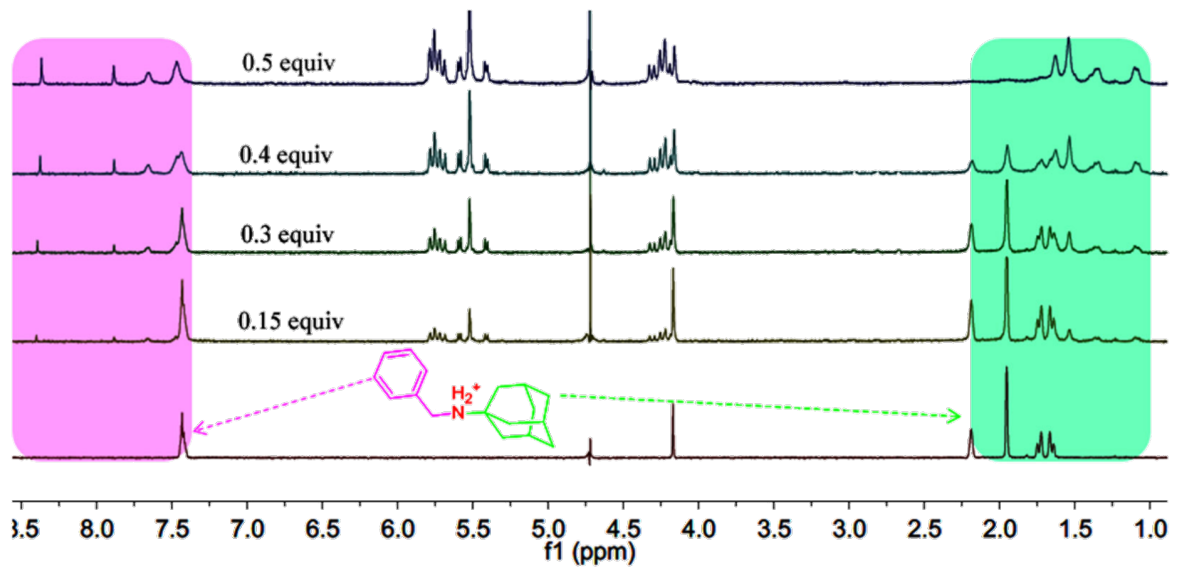

Figure 1: ${ }^{1} \mathrm{H}$ NMR spectra of $\mathrm{G} 1\left(1.0 \mathrm{mmol}, \mathrm{D}_{2} \mathrm{O}, \mathrm{pD}=2.0\right)$ in the presence of host-1 at different concentrations at $298 \mathrm{~K}$.

shows the ${ }^{1} \mathrm{H}$ NMR spectral changes of the $\mathbf{G 1}$ guest in $\mathrm{D}_{2} \mathrm{O}$ $(\mathrm{pD}=2.0)$ in the presence of host-1 at different concentrations. Upon gradual addition of host-1 (0-0.4 equiv) to the solution of G1, the resonances corresponding to the protons on G1 split into two sets of signals. For example, one shifted upfield (ADA moiety) or downfield (benzyl moiety), and one remained at the original position. This result may be attributed to the slow movements of complexed and uncomplexed forms of G1 with host-1 on the NMR time scale; therefore, free G1 and the G1.host-1 complex were individually observed. With increasing concentrations of host-1 to ca. 0.5 equiv (Figure 1), the original proton signal disappeared. In particular, the peak of the protons on the ADA moiety shifted upfield from $\delta 2.23-1.65 \mathrm{ppm}$ to $\delta 1.60-1.09 \mathrm{ppm}$, whereas the signals for the protons on the benzyl group substantially shifted downfield from $\delta 7.44 \mathrm{ppm}$ to $7.48,7.65,7.89$, and $8.38 \mathrm{ppm}$. These results suggest that host-1 cavities encapsulated the ADA moiety of G1 (upfield shift due to the shielding effect of the hydrophobic cavity) and that the benzyl group was on or near the host-1 portal (downfield shift due to the deshielding effect of the carbonyl-rimmed portal). Isothermal titration calorimetry results reveal a $2: 1$ G1/host-1 stoichiometry with a binding constant $\left(K_{\mathrm{a}}\right)$ of $1.32 \times 10^{5} \mathrm{M}^{-1}$ (Table 1$)$. These observations clearly indicate that host-1 recognizes and prefers to include the ADA moieties in both of the identical cavities with homotropic allostery effect.

In the case of the ${ }^{1} \mathrm{H}$ NMR titration experiments for host-guest interactions of G1-host-2, the chemical shift changes in G1 with increasing host-2 concentration are similar to those observed in the host-1 systems. However, the largest difference in the host-guest interaction properties between G1·host-2 and G1.host-1 is that the proton peaks on the benzyl group of G1 undergoes a large upfield shift (from $\delta 7.44 \mathrm{ppm}$ to 6.75 and
$6.37 \mathrm{ppm}$ ), as well as a slight proton downfield shift of the ADA moiety in the presence of host-2 (Figure 2). These spectral changes suggest that $\mathbf{G 1}$ accommodated its benzyl group into the cavities and that the ADA moiety remained in the portal of host-2, forming ternary complexes. These findings are also consistent with the behaviors observed by Isaacs and co-workers. That is, the bridging imidazolidone units of host-2 rigidify the structure of host-1, which has the ability to expand its cavity to accommodate larger guests. This effect makes it selective toward small guests [12].

As mentioned previously, Isaacs and co-workers reported their pioneering work on the host-guest interaction properties of host-1 and -2. Several diastereomers of some guests such as ADA were observed within ternary complexes of host-1 by ${ }^{1} \mathrm{H}$ NMR spectroscopy [23]. However, when we appended the benzyl group to the ADA moiety (G1) in the present study, the ${ }^{1} \mathrm{H}$ NMR spectra cannot provide the related proton signals that distinguish the possible diastereomers of $\mathbf{G 1}$ in host-1 and host2, despite the clear split of resonances corresponding to the protons on the hosts.

A number of studies suggest that pyrene is one of the most useful fluorogenic units, being sensitive to conformational change because of its relatively efficient monomer and excimer emissions [30]. For example, when pyrene instead of the benzyl group was appended to the ADA moiety (G2) in the present work, the top-center diastereomers of ADA-based derivatives within the host cavities could be distinguished by the novel photophysical property of pyrene (Scheme 2 ).

Figure 3a shows changes in the fluorescence emission spectra of $\mathbf{G 2}$ in the presence of host-1. As can be seen, free G2 produced typical monomer emissions at around 378 and $396 \mathrm{~nm}$ in 


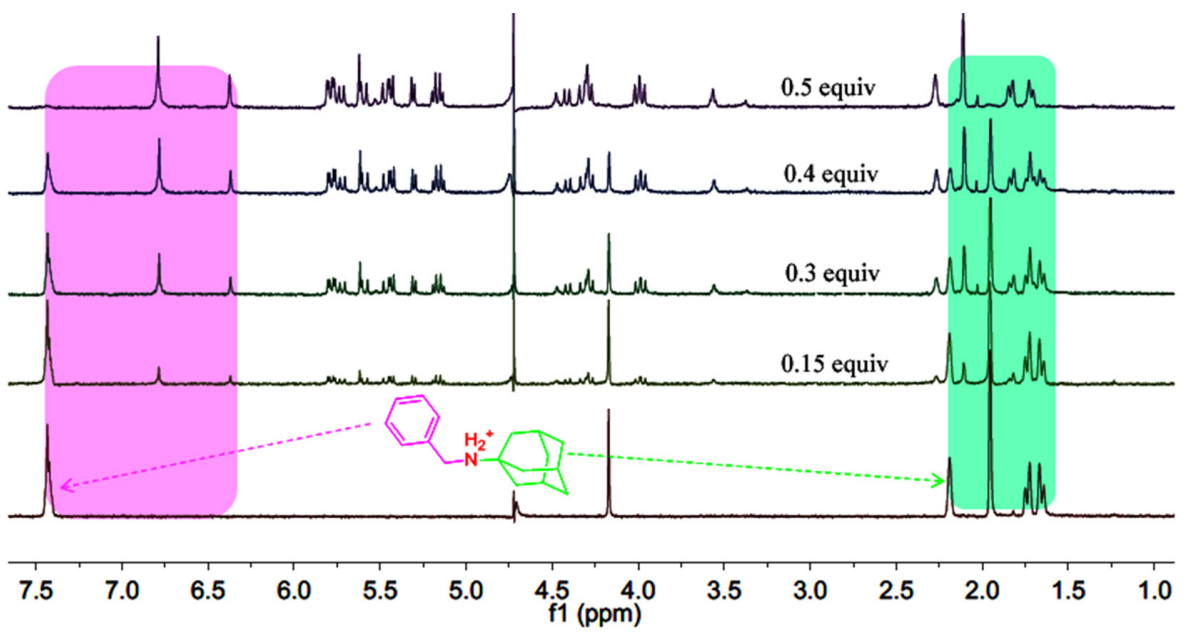

Figure 2: ${ }^{1} \mathrm{H}$ NMR spectra of $\mathrm{G} 1\left(1.0 \mathrm{mmol}, \mathrm{D}_{2} \mathrm{O}, \mathrm{pD}=2.0\right)$ in the presence of host-2 at different concentrations at $298 \mathrm{~K}$.

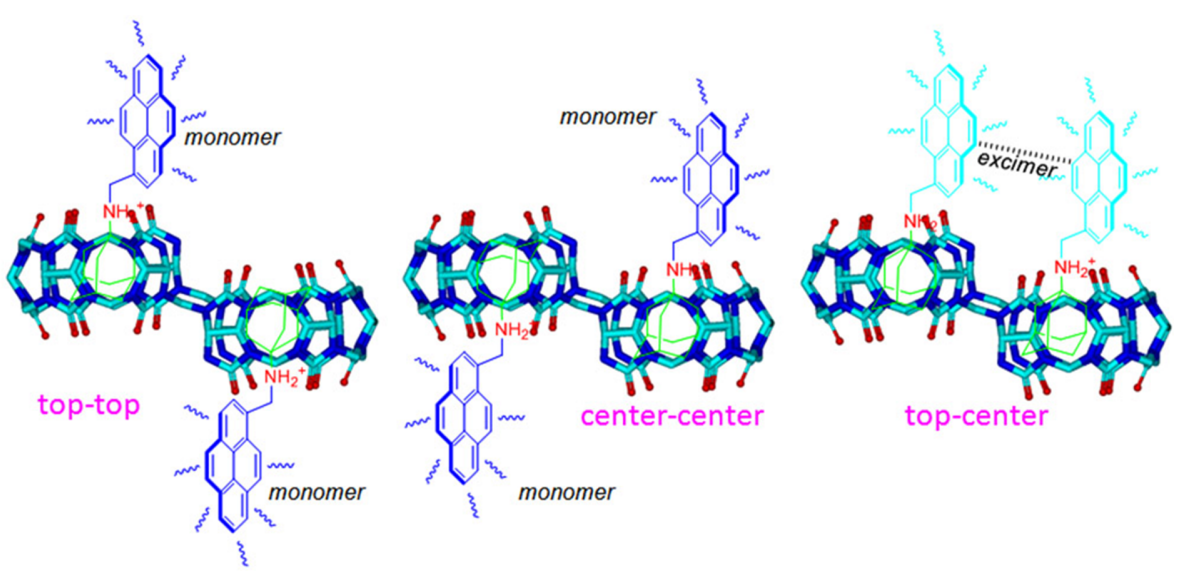

Scheme 2: Plausible diastereomers showing the fluorescence response of G2 with host-1.
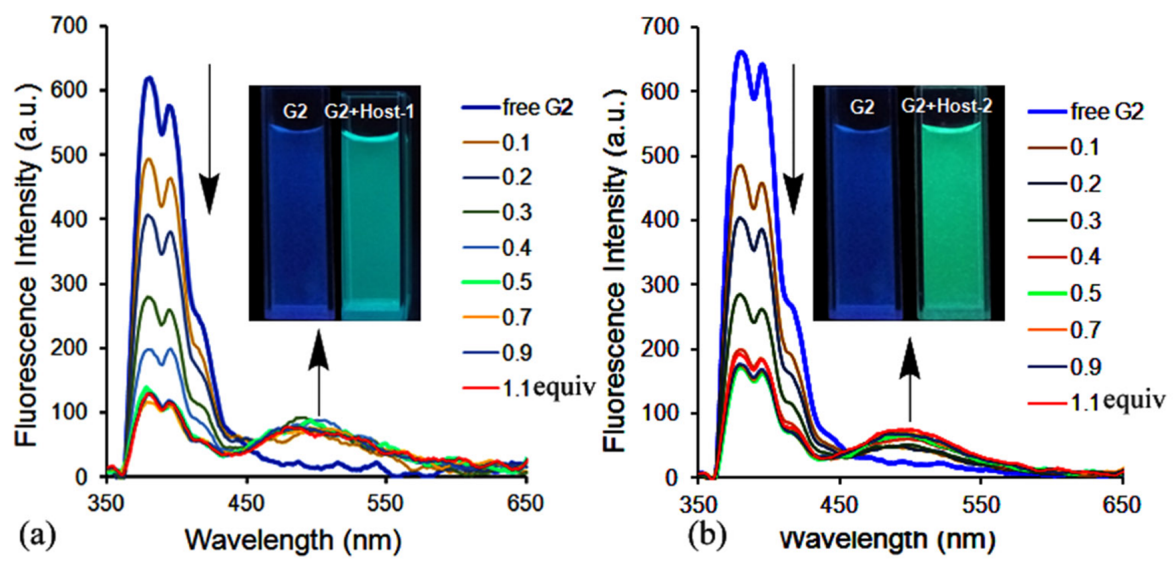

Figure 3: Fluorescence spectral changes of $\mathbf{G 2}(10.0 \mu \mathrm{M})$ in the presence of host-1 (a) and host-2 (b) at different concentrations in aqueous solution $(\mathrm{pH} 2.0)$ at $298 \mathrm{~K}$. 
aqueous solution ( $\mathrm{pH}$ 2) upon excitation of the pyrene fluorophore at $340 \mathrm{~nm}$. When we added host-1 at increasing concentrations to the $\mathbf{G 2}$ solution, the fluorescence intensity of the G2 monomer emissions gradually decreased, while the maximum emission intensity at around $485 \mathrm{~nm}$ (typical excimer emissions of pyrene) increased. The excimer emission band of $\mathbf{G 2}$ can be attributed to the interaction of two pyrene units resulting in intermolecular $\pi-\pi$ stacking, which was due to the two identical cavities of host-1. Consequently, the top-center isomerism of the G2·host-1 ternary complexes was conveniently confirmed from the optical signal after the changes in monomer/ excimer fluorescence emissions of the pyrene groups on G2 Surprisingly, the fluorescence spectral changes of G2 (Figure 3b) suggest that a similar host-guest interaction triggered monomer-to-excimer binding response between $\mathbf{G 2}$ and host $\mathbf{2}$, similar to host $\mathbf{1}$ with $\mathbf{G 2}$, when we attempted to add host-2 to the $\mathbf{G 2}$ solution under the same conditions. Both of the complexes of $\mathbf{G 2}$ with the host-1 ad host-2 were further studied by UV-vis spectra (Supporting Information File 1, Figure S3) and Job plot (Supporting Information File 1, Figure S4).

In order to obtain detailed information on the mechanism of the complexation of G2 with host-1 and -2, ${ }^{1} \mathrm{H}$ NMR titration experiments in acidic aqueous solution were carried out. The spectral changes are shown in Figure 4. Upon addition of 0.5 equiv of host-1 to the solution of $\mathbf{G 2}$, the chemical shift of some protons on the ADA moiety and pyrene group shifted upfield. Expectably, the upfield shift of ADA protons can be ascribed to the cavity's encapsulation of this moiety. Pyrene group, that are too large for the individual $\mathrm{CB}[6]-\mathrm{CB}[7]$ sized cavities of
ns-CB[10] [23], it is thus believed that the upfield shift of the pyrene protons is attributed the intermolecular $\pi-\pi$ stacking between the two pyrenyl moieties as proposed in the plausible inclusion modes in Scheme 2. Importantly, the ${ }^{1} \mathrm{H}$ NMR spectral changes indicate that the rigid cavities of host-2 can accommodate the ADA moiety of G2 (Supporting Information File 1, Figure S5). The upfield shift of protons on the ADA moiety can be observed despite the fast formation of a precipitate upon the addition of host-2 to a $\mathbf{G 2}$ solution. This result is very different from our previous observations on the host-guest interactions of $\mathbf{G 1}$ with host-2 and those of a study on ADA with host-2 by Isaacs and co-workers. In both cases, the ADA moiety was always rejected by the cavity of host-2.

Generally, the recognition binding ability for $\mathrm{Q}[n] \mathrm{s}$ in aqueous solution is mainly due to the attraction between $\mathrm{Q}[n]$ hosts and guest based on the size or shape complementarily. This ability is aided by ion-dipole and dipole-dipole interactions arising from the electron-rich carbonyl rims of $\mathrm{Q}[n] \mathrm{s}$, the nonclassical hydrophobic effect of $\mathrm{Q}[n] \mathrm{s}$, and the classical hydrophobic effect of the guest [31-33]. The desolvation of the $\mathrm{Q}[n]$ host cavity delivers high-energy water trapped in the cavity; as it has a favorable enthalpic signature, this is a nonclassical hydrophobic effect. Contrary to that, the desolvation of the guest molecules is a classical hydrophobic effect; it has a favorable entropic component due to the delivery of surface-bound solvent molecules on the guest. Therefore, isothermal titration calorimetry could be employed to quantify the enthalpic and entropic contributions to the binding interactions between the hosts and guests (results are shown in Table 1 and Figures S6 and S7 in

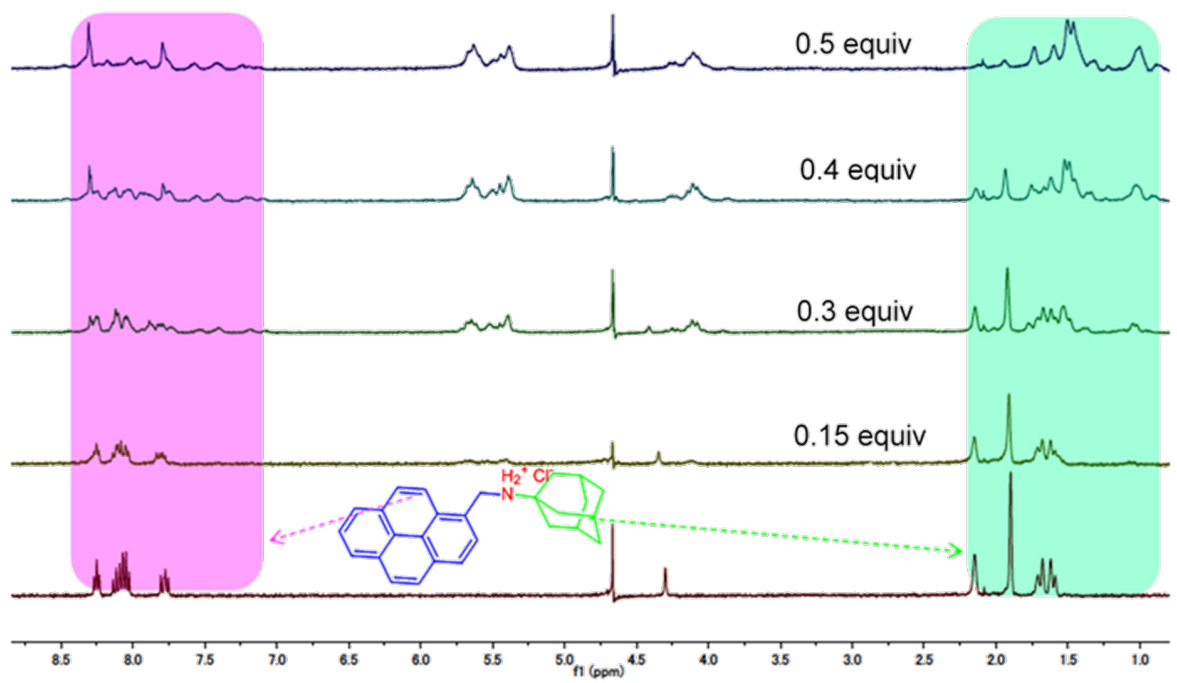

Figure 4: ${ }^{1} \mathrm{H}$ NMR spectra of $\mathrm{G} 2\left(1.0 \mathrm{mmol}, \mathrm{D}_{2} \mathrm{O}, \mathrm{pD}=2.0\right)$ in the presence of different concentrations of host-1. 
Table 1: Thermodynamic binding data for G1·host-1, G2·host-1, G1·host-2, and G2·host-2 (error $= \pm 10 \%$ ).

\begin{tabular}{cccccc} 
Guest-host & $n$ & $K_{\mathrm{a}}\left(\mathrm{L} \cdot \mathrm{mol}^{-1}\right)$ & $\Delta G\left(\mathrm{~kJ} \cdot \mathrm{mol}^{-1}\right)$ & $\Delta H\left(\mathrm{~kJ} \cdot \mathrm{mol}^{-1}\right)$ & -50.90 \\
\hline G1·host-1 & 1.92 & $1.32 \times 10^{5}$ & -29.24 & -21.66 \\
G2·host-1 & 1.98 & $7.64 \times 10^{6}$ & -39.3 & -65.77 & -39.01 \\
G1·host-2 & 2.03 & $4.51 \times 10^{6}$ & -37.99 & -30.96
\end{tabular}

Supporting Information File 1). The obtained thermodynamic parameters suggest that the ternary host-guest interactions of host-1 with $\mathbf{G 1}$ and $\mathbf{G 2}$, host-2 with $\mathbf{G 1}$ are almost exclusively enthalpy-driven $\left(\Delta H=-50.90 \mathrm{~kJ} \cdot \mathrm{mol}^{-1}\right.$ and $T \Delta S=-21.66 \mathrm{~kJ} \cdot \mathrm{mol}^{-1}$ for inclusion complex $\mathbf{G 1} \cdot$ host-1; $\Delta H=-65.77 \mathrm{~kJ} \cdot \mathrm{mol}^{-1}$ and $T \Delta S=-26.46 \mathrm{~kJ} \cdot \mathrm{mol}^{-1}$ for the inclusion complex G2.host-1; $\Delta H=-39.01 \mathrm{~kJ} \cdot \mathrm{mol}^{-1}$ and $T \Delta S=-1.02 \mathrm{~kJ} \cdot \mathrm{mol}^{-1}$ for the inclusion complex $\mathbf{G 1} \cdot$ host-2); while only the formation of the inclusion complexes of host-2 with $\mathbf{G 2}$ is driven by both enthalpy and entropy $\left(\Delta H=-30.96 \mathrm{~kJ} \cdot \mathrm{mol}^{-1}\right.$ and $\left.T \Delta S=9.46 \mathrm{~kJ} \cdot \mathrm{mol}^{-1}\right)$. Evidently, the high enthalpy gain for host-1 with $\mathbf{G 1}$ and G2, host-2 with G1 may be attributed to the strong ion-dipole interactions between the guest and host. However, the host-guest interactions in the case of complexes of $\mathbf{G 2}$-host-2 are derived not only from the ion-dipole interactions between the host and guest, but also in the assistant of the hydrophobic effect. Notably, the entropic gain achieved with the G2.host-2 system was higher than that obtained with other host-guest systems, indicating that the large hydrophobic side group pyrene is enabling the classical hydrophobic effect in aqueous solution as the guest indeed. On the other hand, the thermodynamic parameters obtained in the present study also suggest that the rigidify cavity structure such as host-2 is benefit for the classical hydrophobic effect of guest in aqueous solution.

\section{Conclusion}

In summary, we evaluated the molecular recognition triggered by a novel host-guest interaction of NS-CB[10]-based host-1 and host-2. The unique monomer and excimer fluorescence emissions of pyrene due to the two-cavities of the host-guest system were exploited to identify the possible diastereomers. The top-center isomer of the ternary complexes of $\mathbf{G 2}$ with the hosts was eventually identified from the distinct photophysical signals of pyrene. Interestingly, we found that being a large hydrophobic side group on the guests, pyrene plays important roles in improving the guest recognition and the binding ability of the hosts. This study shows that gradually tuning the side groups of the guest molecules from hydrophilic to hydrophobic may provide new insights into the dependence of molecular recognition on the host cavity size in aqueous solution.

\section{Supporting Information}

\section{Supporting Information File 1}

Experimental data, additional ${ }^{1} \mathrm{H}$ NMR spectra and others.

[https://www.beilstein-journals.org/bjoc/content/ supplementary/1860-5397-15-166-S1.pdf]

\section{Acknowledgements}

This work was supported by the National Natural Science Foundation of China (21871063), the Science and Technology Foundation of Guizhou Province (20165656) and Guizhou University $(20175788,20185781)$.

\section{ORCID ${ }^{\circledR}$ iDs}

Xin-Long Ni - https://orcid.org/0000-0002-5557-1631

\section{Preprint}

A non-peer-reviewed version of this article has been previously published as a preprint doi:10.3762/bxiv.2019.19.v1

\section{References}

1. Changeux, J.-P.; Edelstein, S. F1000 Biol. Rep. 2011, 3. doi:10.3410/b3-19

2. Day, A.; Arnold, A. P.; Blanch, R. J.; Snushall, B. J. Org. Chem. 2001, 66, 8094-8100. doi:10.1021/jo015897c

3. Kim, J.; Jung, I.-S.; Kim, S.-Y.; Lee, E.; Kang, J.-K.; Sakamoto, S.; Yamaguchi, K.; Kim, K. J. Am. Chem. Soc. 2000, 122, 540-541. doi:10.1021/ja993376p

4. Barrow, S. J.; Kasera, S.; Rowland, M. J.; del Barrio, J.; Scherman, O. A. Chem. Rev. 2015, 115, 12320-12406. doi:10.1021/acs.chemrev.5b00341

5. Ni, X.-L.; Xiao, X.; Cong, H.; Zhu, Q.-J.; Xue, S.-F.; Tao, Z. Acc. Chem. Res. 2014, 47, 1386-1395. doi:10.1021/ar5000133

6. Bhasikuttan, A. C.; Pal, H.; Mohanty, J. Chem. Commun. 2011, 47, 9959-9971. doi:10.1039/c1cc12091c

7. Yang, X.; Liu, F.; Zhao, Z.; Liang, F.; Zhang, H.; Liu, S. Chin. Chem. Lett. 2018, 29, 1560-1566. doi:10.1016/j.cclet.2018.01.032

8. Jiao, Y.; Li, W.-L.; Xu, J.-F.; Wang, G.; Li, J.; Wang, Z.; Zhang, X. Angew. Chem., Int. Ed. 2016, 55, 8933-8937. doi:10.1002/anie.201603182

9. Cui, X.; Zhao, W.; Chen, K.; Ni, X.-L.; Zhang, Y.-Q.; Tao, Z. Chem. - Eur. J. 2017, 23, 2759-2763. doi:10.1002/chem.201605045 
10. Zhang, Q.; Wang, W.-Z.; Yu, J.-J.; Qu, D.-H.; Tian, H. Adv. Mater. (Weinheim, Ger.) 2017, 29, 1604948. doi:10.1002/adma.201604948

11. Gong, W.; Yang, X.; Zavalij, P. Y.; Isaacs, L.; Zhao, Z.; Liu, S. Chem. - Eur. J. 2016, 22, 17612-17618. doi:10.1002/chem.201604149

12. Mao, D.; Liang, Y.; Liu, Y.; Zhou, X.; Ma, J.; Jiang, B.; Liu, J.; Ma, D. Angew. Chem., Int. Ed. 2017, 56, 12614-12618. doi:10.1002/anie.201707164

13. Wu, W.; Song, S.; Cui, X.; Sun, T.; Zhang, J.-X.; Ni, X.-L. Chin. Chem. Lett. 2018, 29, 95-98. doi:10.1016/j.cclet.2017.08.049

14. Kim, H.-J.; Heo, J.; Jeon, W. S.; Lee, E.; Kim, J.; Sakamoto, S.; Yamaguchi, K.; Kim, K. Angew. Chem., Int. Ed. 2001, 40, 1526-1529. doi:10.1002/1521-3773(20010417)40:8<1526::aid-anie1526>3.0.co;2-t

15. Ko, Y. H.; Kim, E.; Hwang, I.; Kim, K. Chem. Commun. 2007, 1305-1315. doi:10.1039/b615103e

16. Wang, X.-Q.; Lei, Q.; Zhu, J.-Y.; Wang, W.-J.; Cheng, Q.; Gao, F.; Sun, Y.-X.; Zhang, X.-Z. ACS Appl. Mater. Interfaces 2016, 8, 22892-22899. doi:10.1021/acsami.6b07507

17. Li, S.; Jiang, N.; Zhao, W.; Ding, Y.-F.; Zheng, Y.; Wang, L.-H.; Zheng, J.; Wang, R. Chem. Commun. 2017, 53, 5870-5873. doi:10.1039/c7cc02466e

18. Liu, Y.; Yang, H.; Wang, Z.; Zhang, X. Chem. - Asian J. 2013, 8, 1626-1632. doi:10.1002/asia.201300151

19. Tian, J.; Chen, L.; Zhang, D.-W.; Liu, Y.; Li, Z.-T. Chem. Commun. 2016, 52, 6351-6362. doi:10.1039/c6cc02331b

20. Ni, X.-L.; Chen, S.; Yang, Y.; Tao, Z. J. Am. Chem. Soc. 2016, 138, 6177-6183. doi:10.1021/jacs.6b01223

21. Xia, Y.; Chen, S.; Ni, X.-L. ACS Appl. Mater. Interfaces 2018, 10, 13048-13052. doi:10.1021/acsami.8b02573

22. Wu, H.; Chen, Y.; Dai, X.; Li, P.; Stoddart, J. F.; Liu, Y. J. Am. Chem. Soc. 2019, 141, 6583-6591. doi:10.1021/jacs.8b13675

23. Huang, W.-H.; Liu, S.; Zavalij, P. Y.; Isaacs, L. J. Am. Chem. Soc. 2006, 128, 14744-14745. doi:10.1021/ja064776x

24. Nally, R.; Scherman, O. A.; Isaacs, L. Supramol. Chem. 2010, 22, 683-690. doi:10.1080/10610278.2010.497213

25. Nally, R.; Isaacs, L. Tetrahedron 2009, 65, 7249-7258. doi:10.1016/j.tet.2009.02.055

26. Park, K. M.; Roh, J. H.; Sung, G.; Murray, J.; Kim, K. Chem. - Asian J. 2017, 12, 1461-1464. doi:10.1002/asia.201700386

27. Appel, E. A.; del Barrio, J.; Dyson, J.; Isaacs, L.; Scherman, O. A. Chem. Sci. 2012, 3, 2278-2281. doi:10.1039/c2sc20285a

28. Wittenberg, J. B.; Costales, M. G.; Zavalij, P. Y.; Isaacs, L. Chem. Commun. 2011, 47, 9420-9422. doi:10.1039/c1cc13358f

29. Liu, S.; Ruspic, C.; Mukhopadhyay, P.; Chakrabarti, S.; Zavalij, P. Y.; Isaacs, L. J. Am. Chem. Soc. 2005, 127, 15959-15967. doi:10.1021/ja055013x

30. Kim, J. S.; Quang, D. T. Chem. Rev. 2007, 107, 3780-3799. doi:10.1021/cr068046j

31. Biedermann, F.; Uzunova, V. D.; Scherman, O. A.; Nau, W. M.; De Simone, A. J. Am. Chem. Soc. 2012, 134, 15318-15323. doi:10.1021/ja303309e

32. Biedermann, F.; Vendruscolo, M.; Scherman, O. A.; De Simone, A.; Nau, W. M. J. Am. Chem. Soc. 2013, 135, 14879-14888. doi:10.1021/ja407951x

33. Huang, Z.; Qin, K.; Deng, G.; Wu, G.; Bai, Y.; Xu, J.-F.; Wang, Z.; Yu, Z.; Scherman, O. A.; Zhang, X. Langmuir 2016, 32, 12352-12360. doi:10.1021/acs.langmuir.6b01709

\section{License and Terms}

This is an Open Access article under the terms of the Creative Commons Attribution License (http://creativecommons.org/licenses/by/4.0). Please note that the reuse, redistribution and reproduction in particular requires that the authors and source are credited.

The license is subject to the Beilstein Journal of Organic Chemistry terms and conditions:

(https://www.beilstein-journals.org/bjoc)

The definitive version of this article is the electronic one which can be found at:

$\underline{\text { doi: } 10.3762 / \text { bjoc. } 15.166}$ 